\title{
A ECONOMIA DA CULTURA E A MÚSICA COMO LINGUAGEM GERADORA DE NOVOS DESAFIOS JURÍDICOS
}

\section{CULTURE ECONOMIC AND MUSICAL LANGUAGE AS GENERATOR OF NEW LEGAL CHALLENGES}

\author{
${ }^{1}$ Letícia Menegassi Borges
}

\section{RESUMO}

A cultura como um todo e mais especificamente a música são rapidamente influenciadas pelas novas tecnologias. O conceito constitucional de cultura é amplo e exige do Estado uma postura ativa no sentido de garantir a democratização de acesso, tanto por se tratar de um direito, como por ser um fator econômico relevante, a "economia da cultura". Nesse contexto, a música é uma linguagem que gera novos desafios jurídicos na medida em que a tecnologia ameaça certos interesses anteriormente consolidados e abre novas possibilidades em seus modos de produção e circulação.

Palavras-chave: Cultura, Música, Estado, Constituição

\begin{abstract}
The whole culture and more specifically music are quickly influenced by new technologies. The constitutional concept of culture is ample and requires from the State an Active posture in order to guarantee the democratization of access, both for being a right, and also for being a relevant economic factor, the "culture of economics ". In this context, music is a language that generates new legal challenges as far as technology menaces certain interests before consolidated and opens new possibilities in its production and circulation modes.
\end{abstract}

Keywords: Culture, Music, State, Constitution

\footnotetext{
${ }^{1}$ Mestre em Direito Político e Econômico pela Universidade Presbiteriana Mackenzie - UPM, São Paulo, Brasil. Pesquisa e Desenvolvimento pela Universidade Presbiteriana Mackenzie. E-mail: leticiamenegassi@yahoo.com.br
} 


\section{INTRODUÇÃO}

A cultura e a tecnologia são fenômenos dinâmicos, que tendem a influenciar e ao mesmo tempo serem influenciadas pela sociedade e pelo mercado em ritmo bastante rápido. A música, por ser uma linguagem artística, tende a ser diretamente influenciada por esses fenômenos.

O termo "cultura" aqui empregado tem na Constituição Federal de 1988 o seu conceito, qual seja, um conceito amplo e pluralista, que desde o seu preâmbulo ${ }^{1}$ afasta de plano qualquer intenção em se falar em uma única cultura pretensamente verdadeira ou universal. Isso porque, a cultura é a manifestação de valores do povo em seus diferentes contextos sociais, geográficos, religiosos e econômicos, por meio do conjunto de fazeres e saberes acumulados ao longo do tempo. Tal concepção pode ser observada, por exemplo, no parágrafo 1. ${ }^{\circ}$, do art. 215 e art. 216, ambos da Constituição Federal de 1988.

Ademais, na Constituição Federal de 1988, a cultura (e dentro dela, a música) passa a ser objeto do direito positivado e um direito de todos. A proteção da cultura, a sua valorização, bem como o acesso à cultura, então, revela-se como um dos elementos da dignidade da pessoa humana, inclusive porque também se relaciona com o desenvolvimento econômico do País, o que pode ser observado no estudo da chamada economia da cultura.

Todavia, em decorrência de inovações tecnológicas concebidas nos últimos anos o mercado da música vem passando por diversas mudanças, sejam em suas formas de produção, ou sejam em suas formas de consumo. Em consequência de tais mudanças, surge para os operadores do direito desafios diretamente ligados a esse contexto.

\section{A CULTURA E O SEU RELEVO ECONÔMICO: A ECONOMIA DA CULTURA}

A cultura passa a ser objeto de atenção do direito e das políticas públicas na medida em que se destaca como um importante elemento de desenvolvimento econômico, a ponto

\footnotetext{
1 "Nós, representantes do povo brasileiro, reunidos em Assembléia Nacional Constituinte para instituir um Estado Democrático, destinado a assegurar o exercício dos direitos sociais e individuais, a liberdade, a segurança, o bem-estar, o desenvolvimento, a igualdade e a justiça como valores supremos de uma sociedade fraterna, pluralista e sem preconceitos, fundada na harmonia social e comprometida, na ordem interna e internacional, com a solução pacífica das controvérsias, promulgamos, sob a proteção de Deus, a seguinte CONSTITUIÇÃO DA REPÚBLICA FEDERATIVA DO BRASIL" (grifos nossos).
} 
de merecer a alcunha de "economia da cultura", sendo ponto de atenção nacional e internacionalmente ${ }^{2}$.

Primeiramente, é preciso ter em mente que a economia da cultura não é necessariamente coincidente com o conceito de indústria cultural estabelecido pelos filósofos da Escola de Frankfurt, Theodor Adorno e Max Horkheimer. Para estes (1985, p. 103), a cultura contemporânea tem como característica a sua dimensão industrial, sua relevância reside justamente em seu impacto no plano político e econômico e sua difusão passa a ter alcance mundial, mesmo que sua produção em escala industrial se dê em alguns poucos países industrializados. Isso acontece principalmente após a II Guerra Mundial, com o surgimento de novos ramos de atividade como a televisão, as técnicas de gravação em vídeo, a informática, que dão cada vez mais poder à indústria cultural.

Porém, esse mesmo processo de industrialização da cultura faz com que ela se torne cada vez mais condicionada às exigências do mercado, pois passa a ser oferecida em formas de produtos e serviços, atendendo aos seus ditames. Além de ter a característica de ser uma mercadoria, a cultura contemporânea, na visão da Escola de Frankfurt, passa a ser um instrumento de controle social, ou seja, como um meio de construir opiniões, desejos etc (ADORNO; HORKHEIMER, 1985, p. 100).

Assim, pode-se dizer que há indústria cultural quando os bens e serviços culturais se produzem, reproduzem, conservam e difundem a partir de critérios industriais e comerciais, não apenas com vistas à criação cultural desvinculada de tais critérios (ANVERRE et al., 1982, p. 18). Isso não fica tão claro nos países já desenvolvidos, mas é mais visível nos países em desenvolvimento, já que estes costumam sofrer a difusão maciça da produção cultural de países desenvolvidos. A visão da Escola de Frankfurt é bastante crítica quanto à indústria cultural.

Por outro lado, é bem verdade que os instrumentos tecnológicos que permitem a existência de uma indústria cultural, permitem, ao mesmo tempo, a um número muito grande de pessoas, o acesso à cultura (se não qualitativa, ao menos quantitativamente), e assim

\footnotetext{
${ }^{2}$ Exemplo de como a economia da cultura tem merecido atenção foi a reunião realizada entre o Ministro de Estado da Cultura do Brasil e a Ministra de Estado da Cultura e Mídia da Alemanha, em 20.08.2015. Na ocasião, o Ministro brasileiro Juca Ferreira afirmou que "A agenda do século XXI para a Cultura brasileira passa imprescindivelmente pela cultura digital e economia da cultura". Ver mais em: $<$ http://www.cultura.gov.br/banner-1/-/asset_publisher/G5fqgiDe7rqz/content/brasil-e-alemanhadebatem-economia-da-cultura/10883?redirect=http://www.cultura.gov.br/banner1\%3Fp_p_id\%3D101_INSTANCE_G5fqgiDe7rqz\%26p_p_lifecycle\%3D0\%26p_p_state\%3Dnorma 1\%26p_p_mode\%3Dview\%26p_p_col_id\%3Dcolumn-1\%26p_p_col_count\%3D4>. Acesso em: 13 set. 2015.
} 
movimentam a economia e geram um enorme mercado de trabalho para artistas e produtores em geral (GIRARD apud ANVERRE et al., 1982, p. 21).

Apesar disso, o estudo da economia da cultura demorou para ser iniciado pela ciência econômica (TOLILA, 2007, p. 26). Um dos motivos para que a teoria econômica somente se debruçasse sobre a economia da cultura tardiamente, é o fato de que o valor econômico dos bens culturais é de difícil mensuração. Nas palavras do autor:

Os economistas perceberam, com justa razão, que os bens culturais e artísticos escapam, em grande parte, desse modelo da mercadoria-tipo, porque o que constitui sua definição, a qualidade artística, responde a uma avaliação subjetiva e não a uma medida cuja universalidade poderia ser consensual.

O conteúdo artístico de um bem em relação a outro não pode ser objeto de uma classificação objetiva nem de uma hierarquização universal.

(TOLILA, 2007, p. 29) (grifos do autor)

Ou seja, ao contrário de outras mercadorias, o bem cultural não se exaure em seu consumo, e sua qualidade é algo extremamente subjetivo. Além disso, há de se ter em mente que a produção cultural é incerta do ponto de vista da qualidade, pois este é um fator não suscetível de um controle, ao contrário do que ocorre com as mercadorias industrializadas, e que o custo envolvido em sua produção não se relaciona necessariamente com o valor final do produto.

Somente após a compreensão dessas suas características peculiares é que a cultura começou a ser tratada nos campos da economia e das políticas públicas como uma geradora de riquezas. Portanto, tanto o conceito de economia da cultura, que ainda está em evolução, quanto o seu estabelecimento como disciplina de estudo são bastante recentes (INSTITUTO DE PESQUISA ECONÔMICA APLICADA - IPEA, 2013, p. 8).

Entretanto, não é apenas sob o aspecto econômico propriamente dito que a economia da cultura se torna importante, mas também pela sua capacidade de proporcionar acesso à cultura a um grande número de pessoas, sendo então objeto de políticas públicas. Na atualidade, essa característica é intensificada pela profusão de instrumentos tecnológicos aptos a proporcionar o contato do público com as criações artísticas, sobretudo no campo da música e do audiovisual.

Uma importante consequência do fato de a economia da cultura passar a ser reconhecida pela ciência econômica é que começa a se dar cada vez mais importância para a obtenção de dados mostrando a relevância da cultura na obtenção de receitas tributárias, na geração de empregos e consequentemente na geração de renda. Tais dados são importantes não 
apenas para o próprio mercado da economia da cultura, mas também para nortear o desenvolvimento de políticas públicas e ainda para que haja parâmetros de avaliação dessas políticas públicas.

A Organização das Nações Unidas para Educação, Ciência e Cultura (UNESCO) elaborou o relatório intitulado Creative Economy Report 2013 special edition: widening local development pathways ${ }^{3}$ dedicado a analisar a economia da cultura, partindo do pressuposto de que há uma necessidade urgente de encontrar novas vias de desenvolvimento que incentivem a criatividade e a inovação na busca de crescimento e desenvolvimento inclusivo, equitativo e sustentável, uma vez que a economia da cultura, além de contribuir para esses objetivos gerando riquezas, tem importância também pelos seus valores não monetários (UNESCO, 2013, p. 18).

O referido relatório da UNESCO mostrou que a cultura tem muito potencial enquanto fator de desenvolvimento, pois restou evidenciado que existe uma considerável, forte e valiosa produção no âmbito da economia da cultura. É importante mencionar que o relatório em comento não se ocupou somente dos resultados econômicos isoladamente considerados, mas também com indicadores de eficácia dirigidos aos responsáveis pela elaboração de políticas públicas para a economia da cultura em nível local para que estes possam avaliar e monitorar os resultados dessas pesquisas.

Especificamente em relação ao Brasil, o Creative Economy Report 2013 special edition destacou que já há aqui um esforço significativo do Estado para estimular a economia da cultura em âmbito federal, estadual e municipal. Nesse aspecto, uma das ações mais concretamente visíveis no Brasil para estimular a economia da cultura é o financiamento de atividades e empreendimentos culturais por meio do "Programa BNDES para o desenvolvimento da Economia da Cultura - BNDES Procult" com financiamento no valor mínimo de um milhão de reais ${ }^{4}$.

Esse é um dos exemplos de como o Brasil busca o estímulo à economia da cultura, embora tal estímulo ainda seja incipiente e difícil de mensurar em razão da escassez de dados. Além de relatórios destinados a levantar dados relativos à economia da cultura no âmbito internacional, há também um esforço por parte do Brasil nos últimos anos para construir uma base de dados para o setor.

3 Disponível em: <http://www.unesco.org/culture/pdf/creative-economy-report-2013.pdf>. Acesso em: 25 set. 2015.

4 Ver mais informações sobre o "Procult" no sítio eletrônico do BNDES. Disponível em: http://www.bndes.gov.br/SiteBNDES/bndes/bndes_pt/Areas_de_Atuacao/Cultura/Procult/index.ht ml. Acesso em: 26 set. 2015. 
O Instituto de Pesquisa Econômica Aplicada (IPEA), em pesquisa divulgada no ano de $2013^{5}$, mostra, em resumo, os seguintes resultados: a média dos salários dos trabalhadores que exercem ocupações criativas são maiores que a média dos trabalhadores formais; a maior parte desses trabalhadores da economia criativa está no Estado de São Paulo; os Estados Unidos da América empregam 5,6 vezes mais trabalhadores em ocupações criativas que o Brasil. Por exemplo, o setor de filme e vídeo nos Estados Unidos emprega mais de dez vezes o empregado no Brasil; a escolaridade dos trabalhadores da economia criativa é mais alta do que a média dos trabalhadores de outros setores da economia nacional; em relação ao tempo médio de emprego (em meses), a pesquisa mostrou que os trabalhadores da economia criativa permanecem menos tempo no emprego do que a média dos trabalhadores de outras áreas, de modo que a rotatividade costuma ser alta nesse segmento; os trabalhadores na economia criativa são mais jovens que a média dos trabalhadores das demais áreas. Outro dado interessante trazido à luz pelo IPEA é que a participação da economia criativa no Brasil até o ano de 2009 variou entre $1,2 \%$ e $2 \%$ do Produto Interno Bruto (PIB) e que, em comparação com os países europeus, por exemplo, essa participação é significativamente menor (IPEA, 2013, p. 40).

Apesar da relevância dos dados expostos pelo IPEA, deve-se admitir que os resultados podem ser maiores em razão da informalidade no setor. Apesar da dificuldade para se mensurar o mercado informal da cultura, o IPEA estima que a economia criativa responde por $3 \%$ da força de trabalho brasileira e 6\% da massa salarial no Brasil (IPEA, 2013, p. 46).

Nesse sentido, é espantoso que a economia da cultura ainda não seja tratada pelo Estado brasileiro com a merecida atenção, seja pelo seu valor cultural isoladamente considerado, seja enquanto mercado gerador de riqueza, que por si só já tem o condão de contribuir enormemente para a redução das desigualdades sociais, atingimento do desenvolvimento nacional e, em última análise, para o alcance da cidadania, que está entre os fundamentos da República, consoante arts. $1 .^{\circ}$ e $3 .^{\circ}$ da Constituição Federal. Tanto é verdade o desprezo e ao mesmo tempo a relevância econômica da cultura, que Alfredo Bertini (2008) observa que, por mais que o impacto econômico da cultura seja relevante, ainda assim, tanto a produção quanto o consumo de cultura, no senso comum, são vistos como um “não fazer", isto é, como algo não produtivo.

Vale fazer a ressalva de que, para o referido autor, a separação entre a cultura e o entretenimento enquanto fatores de relevância econômica revela uma visão purista e elitista da cultura, fazendo com que os pesquisadores em geral tenham alguma dificuldade em associar a

5 Disponível em: <http://repositorio.ipea.gov.br/bitstream/11058/2026/1/TD_1880.pdf〉. Acesso em: 07 nov. 2015. 
cultura à economia. Talvez por isso, tenha havido uma carência histórica de políticas públicas consistentes voltadas ao setor cultural, o que não mais se coaduna com a realidade econômica do mercado cultural, e tão pouco se harmoniza com o contexto da globalização e com o surgimento de novas tecnologias, com a necessidade de valorização e proteção da cultura nacional da influência cultural maciça dos mercados dominantes ${ }^{6}$.

A música se destaca como elemento cultural e linguagem artística reveladora de mudanças de hábitos culturais e de consumo, afetando o mercado em via de mão dupla, já que afeta e é ao mesmo tempo afetada, mostrando-se especialmente vulnerável a esse contexto global. Sem se perder de vista os valores acima destacados, bem como os deveres do Estado de proteção e incentivo à cultura, na esteira da revolução tecnológica em que vivemos, a cadeia de produção e comercialização de músicas tem sido amplamente modificada.

Assim, a maior possibilidade de consumo pelo lazer, bem como os efeitos econômicos provocados pelas novas tecnologias, que têm transformado o mercado fonográfico não apenas no Brasil, mas globalmente, o direito de acesso à cultura, bem como os direitos de autor encontram-se em situação paradoxal: ao mesmo tempo em que a internet propiciou um contato com a música sem precedentes na história da humanidade ${ }^{7}$, os direitos autorais nunca estiveram tão ameaçados pela pirataria, seja na venda de CDs copiados ilegalmente, seja na prática de downloads ilegais.

Concomitantemente ao surgimento de novos modelos de negócios, a indústria fonográfica resiste e cobra dos governos uma solução jurídica para esse momento de crise no qual o público em geral se regozija com as facilidades permitidas pela tecnologia que, em muitos casos, não é produzida pelas grandes gravadoras. Aliás, conforme observado por Fabiano Del Masso (2007, p. 22), as técnicas de produção mudam ao longo do tempo, mas não são elas que caracterizam a atividade econômica, e sim a satisfação das necessidades humanas, dentre as quais tomamos a liberdade de inserir a cultura, e notadamente a música.

Conforme será exposto adiante, os agentes econômicos que participam da indústria fonográfica (e não apenas os artistas), buscam assegurar sua hegemonia, ainda que as novas

6 Apenas para que se tenha ideia da rapidez com que a música é propagada atualmente, possibilitada pela internet e pelos novos recursos tecnológicos inventados, na biografia de Steve Jobs, escrita por Walter Isaacson (2011), este relata que, quando o Ipod foi lançado, havia a expectativa de que fossem vendidas 1 milhão de músicas por meio da loja virtual iTunes no período de seis meses. Entretanto, essa quantidade de músicas foi vendida em apenas seis dias.

${ }^{7}$ Em 6 de fevereiro de 2013, a Apple anunciou que foi atingida a marca de 25 bilhões de downloads de músicas baixadas por meio do iTunes. Ver nota oficial da empresa em $<$ http://www.apple.com/pr/library/2013/02/06iTunes-Store-Sets-New-Record-with-25-BillionSongs-Sold.html>. Acesso em: 14 jul. 2015. 
tecnologias tenham relativizado a sua importância no que tange à circulação da música, sendo esta aqui considerada enquanto bem de consumo. Ao mesmo tempo, não é incomum que os artistas contemporâneos se adequem a essa realidade, tratando de disponibilizar espontaneamente sua criação na internet gratuitamente ou por meio de plataformas digitais de baixo custo, abalando significativamente as estruturas desse mercado, que parecia tão consolidado nas décadas de 1980 e 1990.

Enfim, a cultura aqui empregada como sinônimo de arte é um bem jurídico a ser protegido e incentivado pelo Estado, o que no Brasil se torna mandatório a partir da inserção dos direitos culturais na Constituição Federal do 1988; a globalização e a criação de novas tecnologias permitem uma troca cada vez mais intensa de informações, tanto em razão da pirataria quanto em razão da perda do poder econômico das grandes gravadoras, sendo que a indústria fonográfica se encontra em plena transformação em razão desse cenário; e, como se verá adiante, a música oferece à fenomenologia jurídica o surgimento de novos desafios jurídicos, seja no campo da configuração dos contratos entre artistas e gravadoras, seja nos atos de concentração que se verificam nas fusões entre gravadoras, do lobby legislativo feito pelas gravadoras e por artistas do ramo musical para que uma proteção maior lhes seja dada em face da pirataria, ou seja, da contrafação, definida pela Lei n. ${ }^{0}$ 9.610/1998 como "a reprodução não autorizada", da proteção dos direitos autorais e, no caso brasileiro especificamente considerado, também irradiam seus efeitos sobre o sistema tributário nacional por meio da criação da imunidade tributária dos fonogramas e videofonogramas de música brasileira introduzida pela Emenda Constitucional n. ${ }^{\text {o }} 75$ de 15/10/2013.

Em face de certos princípios da ordem social e econômica instituídos na Constituição Federal de 1988, a força econômica da cultura deve ser tratada com atenção na medida em que, quanto maior o poder econômico dos protagonistas desse mercado, mais vulneráveis ficam os interesses do consumidor e até mesmo do Estado, visto que este precisa lidar com esse poder para desenvolver suas políticas públicas.

\section{A MÚSICA COMO GERADORA DE NOVOS DESAFIOS JURÍDICOS}

Quando se pensa em cultura e tecnologia, o conceito schumpteriano de destruição criadora tem grande aderência (MOREL, 2010, p. 21), pois ambas tendem a construir seus novos paradigmas a partir da destruição ou ao menos da sobreposição dos paradigmas anteriores. Considerando tal característica, as novas tecnologias (em especial a internet) têm colocado desafios para a sobrevivência da indústria fonográfica em seu formato tradicional, na 
medida em que transformam as relações entre o público consumidor/fruidor ${ }^{8}$ de música e a indústria fonográfica, e ao mesmo tempo com os artistas, pois a forma como se produz e se divulga a música atualmente não depende exclusivamente da intermediação de uma gravadora. A forma como o público passou a se relacionar com a música e com os artistas é mais rápida e mais direta.

Hoje, a relação entre músicos e seu público não é necessariamente uma relação de consumo materializada por um objeto físico. Agora essa relação se dá por outros meios que, em grande parte, não envolvem objetos palpáveis. De acordo com o relatório da Federação Internacional da Indústria Fonográfica - IFPI ${ }^{9}$, divulgado em 14 de abril de 2015, enquanto as vendas físicas caíram 8,1\% em 2014 no mundo, as receitas obtidas com as vendas em suportes digitais cresceram $6,9 \%$, passando a representar $46 \%$ das vendas totais de música no mundo, sendo que esse resultado é decorrente, principalmente, do desempenho satisfatório do segmento de subscrição para acesso à música por streaming, que remunera os artistas tanto com o valor das assinaturas quanto com a publicidade.

O mesmo relatório revela que as assinaturas de serviço de streaming já representam $23 \%$ do mercado digital global, tendo obtido $39 \%$ de crescimento em 2014 . O mesmo fenômeno pode ser observado no mercado brasileiro, onde as receitas com música digital já representam $48 \%$ do total de vendas. Além disso, na internet, o consumo de música não se dá apenas por meio da relação de compra e venda, mas também por meio da disponibilização gratuita de arquivos de som e imagem. Na prática, tem-se observado duas tendências: a divulgação da música por meio da internet e a valorização dos shows, isto é, das apresentações de música ao vivo, cujos ingressos são cada vez mais caros ${ }^{10}$.

Ambas essas tendências relativizam a importância dos suportes físicos da música e, por consequência, têm provocado profundas transformações no mercado fonográfico,

8 Empregamos as expressões "consumidor" e "fruidor" em conjunto, por entendermos que o desejo de ouvir música não é necessariamente revelador de uma relação marcada pelas necessidades mais imediatas, como tendem a ser as relações de consumo. A relação do ouvinte com a música tende a ser marcada pela fruição estética, não como sinônimo de gostar, mas como possibilidade de proporcionar a esse "consumidor/fruidor" experiências estéticas significativas, distintas das experiências ordinárias, sendo o conceito de experiência estética construído por John Dewey no livro "Art as experience", publicado primeiramente em 1934. A ideia de uma experiência estética, em síntese, pode ser mais bem entendida no seguinte excerto do autor (1934, p. 22): "Experience is the result, the sign, and the reward of that interaction of organism and environment wich, when it is carried to the full, is a transformation of interaction into participation and communication".

9 Relatório completo disponível em: <http://www.abpd.hospedagemdesites.ws/wpcontent/uploads/2015/01/Digital-Music-Report-2015.pdf>. Acesso em: 08 ago. 2015.

10 A respeito dos fatores que podem aumentar os valores dos ingressos de shows no Brasil, veja-se <http://casperlibero.edu.br/por-que-os-ingressos-de-shows-sao-tao-caros-no-brasil/.> Acesso em: 15 out. 2015. 
ameaçando a hegemonia das maiores gravadoras. Não obstante, a música, muito antes de ser uma mercadoria, faz parte da cultura humana. Portanto, se em grande medida a indústria fonográfica, do alto de seu poder econômico, tem o poder de impor certos gostos musicais e mercantilizar essa linguagem cultural ${ }^{11}$, obviamente cobrando para isso, por outro lado, a música enquanto parte da cultura é uma necessidade humana, pode-se dizer praticamente universal, na medida em que todo povo tem sua música, de modo que valores como a cultura regional, bem como o valor da arte em si mesma (isto é, independentemente de seu valor econômico) são preponderantes para o processo de criação e de fruição da música.

Como consequência, ainda que haja um preço a se pagar pela música, na medida em que a internet, e até mesmo a pirataria, oferecem meios de acesso à música que não passam necessariamente pela relação de compra e venda, o público tem cada vez mais aderido às relações de troca, até mesmo ignorando a ideia de ilegalidade vinculada aos downloads ilegais e à compra de CDs e DVDs piratas ${ }^{12}$.

Os artistas, por sua vez, também têm aderido à internet como meio de divulgação de seu trabalho, disponibilizando arquivos gratuitos para audição (o serviço chamado streaming) e visualização de videoclipes, ou até mesmo para download ${ }^{13}$. Dessa forma, não apenas o poder econômico das grandes gravadoras diminui, mas também o poder de ditar o que será lançado no mercado.

${ }^{11}$ Micael Herschmann (2010, p. 22), citando Negus, afirma que “[...] se por um lado, é verdade que com alguma frequência as grandes gravadoras conseguem conformar uma produção globalizada e massificada em diferentes territórios, por outro, há certo limite da capacidade de penetração desses produtos nos mercados locais".

${ }^{12}$ O IPCLBrasil - Índice de Percepção de Cumprimento da Lei, elaborada pela Fundação Getúlio Vargas, mostra que, no semestre analisado (4\% trimestre/2013 e $1^{\circ}$ trimestre/2014), 63\% dos entrevistados admitiram que compram produtos piratas. Ver relatório completo em: <http://bibliotecadigital.fgv.br/dspace/handle/10438/11861>. Acesso em: 13 jun. 2015. Vale ainda citar uma emblemática sentença proferida pelo Juiz de Direito Roberto Coutinho Borba, da $2^{\text {a }}$ Vara Criminal da Comarca de Alvorada - RS (Processo n. ${ }^{\circ}$ 0094492-67.2010.8.21.0003), que considerou improcedente a denúncia do Ministério Público contra um homem que foi flagrado vendendo DVDs piratas no centro da cidade de Alvorada. De acordo com a sentença absolutória, "A conduta perpetrada pelo agente é flagrantemente aceita pela sociedade e, por tal motivo, impassível de coerção pela gravosa imposição de reprimenda criminal". A sentença foi confirmada em sede de apelação pelo Tribunal de Justiça do Rio Grande do Sul, porém tanto o STF quanto o STJ já se manifestaram no sentido de que a adequação social não tem o condão de afastar a tipicidade da conduta. Nesse sentido, vejam-se os seguintes acórdãos do STJ: AGRESP 2013/0134730-0, AGRESP 2012/0252040-3 e HC 2009/0203910-2, disponíveis por meio de consulta processual no sítio eletrônico <https://ww2.stj.jus.br/processo/pesquisa/?aplicacao=processos.ea $>$. No STF, ver os seguintes acórdãos: HC 120994, HC 118322 e RHC 115986, disponíveis por meio de consulta processual no sítio eletrônico <http://www.stf.jus.br/portal/processo/pesquisarProcesso.asp>.

${ }^{13}$ A maior parte dos artistas disponibiliza música para streaming, e não para download. Podem ser citados como artistas que disponibilizaram duas músicas para download gratuito: Pato Fu, Gaby Amarantos e Led Zeppelin. 
Fatores como criatividade e popularidade são, em certa medida, imprevisíveis e indomáveis pelo poder econômico da indústria fonográfica. Portanto, se a relação entre arte e mercado não é uma relação necessariamente dicotômica, também não se pode dizer que é uma relação inteiramente harmônica. Nessa nova realidade, um dos efeitos colaterais que podem ser observados no mercado fonográfico é uma crescente proximidade entre artistas e o público. Isso porque, até então, a divulgação da música passava necessariamente pela intermediação das gravadoras, o que exigia a existência de um contrato com os artistas cujo modelo normalmente era ditado pelas contratantes.

Com o advento e popularização da internet ${ }^{14}$ que permitem aos músicos comporem e gravarem suas músicas com qualidade significativa, sem necessitarem de um estúdio profissional, a intermediação das gravadoras passa a não ser mais um requisito para que um artista se torne conhecido do público (embora a profissionalização seja mais difícil quando o artista é autônomo). Isso sem se falar da presença maciça dos artistas nas redes sociais promovendo diretamente seus trabalhos e interagindo com o seu público diuturnamente.

Tais mudanças geram uma série de novos desafios para regulamentação do uso das novas tecnologias, e ao mesmo tempo para fomentar e proteger a cultura nacional.

Mencione-se, nesse sentido, que o incentivo à cultura pode ter aspectos muito positivos para a economia e consequentemente para o desenvolvimento socioeconômico do País, pois, como já foi dito, a cultura é um fator potencialmente gerador de riqueza, conforme pode ser observado nos países desenvolvidos, em especial naqueles onde não há um tratamento político hierarquizado entre cultura popular, entretenimento e cultura erudita (HERSCHMANN, 2010, p. 27).

Vale aqui fazer uma pausa para que se veja como a música acompanha o ritmo do capitalismo. Conforme percebido por autores como Karl Polanyi (2011) e por Karl Marx (apud MASCARO, 2013, p. 282), com o advento do capitalismo, tudo se transformou em mercadoria, inclusive o próprio homem, na medida em que este não é a finalidade última das relações de produção, mas sim o meio para a produção de bens.

Com a música não foi diferente. Há muito que a música deixou de se situar no âmbito da pura experiência estética e passou a ser uma mercadoria. Essa mercantilização da música e da cultura só se tornou possível na medida em que novas tecnologias que prescindem da

${ }^{14}$ À guisa de exemplo, citem-se os seguintes aplicativos para dispositivos móveis: Music Studio, mp3 Corte, Audio Evolution Mobile Studio e PocketBand - Social DAW. 
execução da música ao vivo foram sendo desenvolvidas, possibilitando a gravação e reprodução do som, principiando-se pelo fonógrafo inventado por Thomas Alva Edison no ano de $1877^{15}$.

Assim, o que até aqui se deixou consignado é que a música, primeiramente, além de ser uma linguagem artística de grande alcance na sociedade (sobretudo a música popular), com sua difusão por meio de tecnologias de reprodução possibilitou sua plena incorporação ao capitalismo, circulando como uma mercadoria, regendo-se mais pelas leis do mercado do que pela busca de padrões estéticos (TINHORÃO, 2010, p. 260). Por isso, esse mercado que gira em torno da música se encontra em pleno momento de transição, pois as mais recentes tecnologias disponíveis ${ }^{16}$, provocam alteração nas relações existentes.

$\mathrm{Na}$ ordem social, as relações globais e as novas tecnologias também se refletem na ideia de proteção da cultura regional, da qual a música brasileira é erigida ao posto de verdadeiro símbolo nacional. A propósito, José Ramos Tinhorão (2010, p. 315) narra que em 1935, ao criar o programa de rádio informativo oficial “A Hora do Brasill”, o governo do então Presidente da República Getúlio Vargas intercalou a propaganda oficial com apresentações musicais de cantores e instrumentistas famosos àquela época, coisa que foi repetida pelo governo estadunidense em seu programa local "A voz da América". Para o referido autor, esse fato demonstra o papel político que a música popular é capaz de desempenhar, “[...] como símbolo da vitalidade e do otimismo da sociedade em expansão sob o novo projeto econômico implantado com a Revolução de 1930 [...]”.

Aliás, não se pode olvidar que a cultura é uma forma pacífica de dominação (BAGNOLI, 2009), razão pela qual pensar em formas de proteção para a indústria fonográfica nacional é legítimo, uma vez que a cultura nacional, é constantemente ameaçada pelo soft power da cultura estadunidense por meio da música e do cinema, ainda que sem impedir o intercâmbio cultural entre as nações. Esse não é um fenômeno novo, pois, no início do século XX, concomitantemente com o desenvolvimento do capitalismo e o surgimento do mercado fonográfico, e facilitada pela identidade nacional ainda em fase de construção, já era grande a penetração de música norte-americana no Brasil (TINHORÃO, 2010, p. 268).

15 José Ramos Tinhorão, em seu livro Música Popular: do gramofone ao rádio e TV (2014, p. 15), relata que, inicialmente, nem mesmo Thomas Edison, ao inventar o fonógrafo, vislumbrou a revolução musical que seria viabilizada por sua invenção. Para Edison, o fonógrafo seria útil para que os empresários ditassem cartas comerciais e para auxiliar na alfabetização de crianças.

${ }^{16}$ Empresa de internet cujo sítio eletrônico é especializado na transmissão de vídeos. Segundo as estatísticas divulgadas pelo próprio Youtube, desde o seu lançamento, em maio de 2005, o site já tem mais de um bilhão de usuários, e já foi pago mais de um bilhão de dólares em direitos autorais para os titulares de direitos decorrentes de vídeos. Ver mais em <https://www.youtube.com/yt/press/ptBR/statistics.html>. Acesso em: 05 out. 2015. 
Antes da invenção do fonógrafo e do rádio, a relação do público com a música se dava muito mais no âmbito da fruição estética do que no âmbito comercial. Isso sem se falar que a reprodução da música dependia da presença de instrumentos musicais, de partituras e de alguém que soubesse manusear esse aparato. Somente com a inovação tecnológica é que foi possível difundir a música entre pessoas que não estavam presentes no local e no momento de sua execução. Foge aos limites deste artigo pontuar historicamente cada tecnologia usada para difundir a música durante o século XX, razão pela qual não se fará um quadro dos suportes utilizados. A luta pelo respeito aos direitos autorais na indústria fonográfica ganha escala cada vez maior, à medida que se multiplicam os instrumentos tecnológicos que facilitam a pirataria. Nessa luta da indústria fonográfica pela sobrevivência e contra a divulgação ilícita da música por meio da internet, vale aqui mencionar o importante capítulo da criação do Ipod e da Itunes Store pela Apple Inc.

Na biografia de Steve Jobs, o autor Walter Isaacson (2011, p. 415) narra como ele convenceu as gravadoras: de cada música vendida, a Apple ficaria 75\% do preço, e o restante seria dividido entre as gravadoras. Jobs argumentou que a pirataria e os downloads ilegais já eram uma realidade e que estavam causando a queda nas vendas de CDs, de modo que a única forma de combater a pirataria, àquela altura, seria vender as músicas separadamente, por meio da Itunes Store. Diante dos argumentos de Steve Jobs e à força dos fatos, a indústria fonográfica acabou aderindo à sua proposta e a popularização da loja virtual de música Itunes Store foi um marco das novas tecnologias como fator de transformação da indústria fonográfica.

Leonardo Morel (2010, p. 35), ao discorrer sobre as inovações tecnológicas que impactaram o mercado musical, exemplifica a necessidade de absorção dessas mudanças ao lembrar que, com o advento do cinema falado, na década de 1930, muitos músicos que costumavam se apresentar em sessões de cinema mudo ficaram desempregados. Além de causar o desemprego, introduzia no Brasil um maior contato com a música estrangeira.

Curioso saber que, à época em que o cinema mudo passou a ser substituído pelo cinema falado abrindo uma crise para os músicos profissionais, a solução proposta tinha viés tributário. Pois, conforme relatado por Virgínia de Almeida Bessa, o Centro Musical do Rio de Janeiro encaminhou um ofício ao então prefeito do município do Rio de Janeiro propondo que os cinemas que não tivessem orquestras tivessem seus impostos aumentados (BESSA, 2005, p. 136). A autora relata ainda que, no mesmo ofício, se propunha a isenção de impostos quando a exibição contasse com um grupo de músicos de ao menos cinco participantes, pelo que os pleitos não foram atendidos. 
Contudo, com o passar do tempo, esse mesmo fato (incorporação do som ao cinema) acabou criando um poderoso canal de divulgação da música, abrindo então novas fronteiras para o desenvolvimento da indústria fonográfica com as trilhas sonoras dos filmes e também com a televisão que futuramente iria despontar. Hoje, não se questiona que a música, o cinema e a televisão andem de mãos dadas. Contudo, em todas aquelas inovações tecnológicas mencionadas acima, a figura do intermediador sempre esteve presente entre o artista e o público, o que garantiu às gravadoras uma posição privilegiada no mercado. Somente com a popularização da internet e com o acesso a programas de computador de criação de música é que o poder desses intermediadores começou a entrar em crise.

Apesar do fato de que os modelos de negócios até então comuns no mercado fonográfico passaram a ser questionados, novos modelos de negócio foram surgindo. Nesse aspecto, talvez seja mais apropriado falar em transição ou adaptação, do que em crise da indústria fonográfica. Outro aspecto que nos permite desconfiar da ideia de crise é o fato de que há uma coexistência entre os antigos e os novos modelos de negócios. É o que se verifica, por exemplo, com o ressurgimento do mercado dos discos de vinil, inclusive com a gravação de novos discos ${ }^{17}$ e com bons resultados nas vendas, até mesmo superando as receitas obtidas por meio das plataformas digitais de streaming ${ }^{18}$. Paralelamente, a televisão, o cinema e o rádio continuam sendo poderosos instrumentos de divulgação de novas músicas.

Assim, apesar de haver algum drama quando se pensa na atual situação da indústria fonográfica, no que tange aos novos modelos de negócios, há todo um universo que se descortina e não somente no universo da internet. De certo modo, pode-se afirmar que a livre iniciativa no campo da música nunca foi tão livre. No contexto desses novos modelos de negócios, Micael Herschmann (2010, p. 84) aponta os seguintes fatores: há atualmente uma valorização dos shows, inclusive com a previsão contratual de participação das gravadoras nas receitas obtidas com ingressos, que estão cada vez mais caros; como o público está cada vez mais resistente em pagar pelos fonogramas de música, os shows têm cada vez mais se transformado em espetáculos, onde o público espera uma experiência estética diferenciada; aumento do número de festivais de música (como o Rock in Rio, Lollapalooza e

\footnotetext{
${ }^{17}$ Notícia divulgada no jornal O Globo em 12/05/2014 com a manchete "Venda de LPs bate recordes no Brasil, EUA e Inglaterra" informa que em 2012, somente nos Estados Unidos, foram vendidas 4,6 milhões de discos de vinil; e em 2013 o número cresceu para 6 milhões em 2013, aumento de $30 \%$. No mesmo período, a venda de CDs caiu 15\%. Disponível em: <http://oglobo.globo.com/cultura/venda-de-lps-bate-recordes-no-brasil-eua-inglaterra12428609\#ixzz3cyQWx4tD>. Acesso em: 13 jun. 2015.

18 Vide a respeito: <http://blogs.estadao.com.br/link/venda-de-vinis-gera-mais-receita-que-servicoscomo-youtube-spotify-e-vevo-juntos/>. Acesso em: 05 out. 2015.
} 
Tomorrowland); o CD passa a ser praticamente um souvenir, uma lembrança da experiência vivida ou elo afetivo entre o artista e o público; fortalecimento das gravadoras independentes (indies) e diminuição da hegemonia das maiores gravadoras (majors).

Do ponto de vista jurídico, novos modelos de contratos vêm sendo impostos aos artistas, sendo muito comum, inclusive, a constituição de pessoas jurídicas nas quais o artista é um produto comercializado, tendo seus lucros divididos conforme a participação dos "investidores" (o próprio artista, seu representante e terceiros que investem dinheiro no artista esperando obter retorno); a contratação de artistas por gravadoras não se baseia mais na comercialização de CDs, mas sim na gestão de licenças e na distribuição de lucros.

Por outro lado, há um movimento no sentido de legitimar novamente a intermediação, para fins de negociação de licenças: o surgimento de plataformas eletrônicas de divulgação, pagas ou gratuitas, como os sites Youtube, Spotify, Deezer, Rádio Uol, Sonora, entre outros exemplos, ainda que essas plataformas não sejam uma unanimidade entre os artistas ${ }^{19}$.

Outro fenômeno interessante também notado por Micael Herschmann (2010) é o crescimento expressivos dos jogos eletrônicos de música, que, além de gerarem receitas significativas, têm o diferencial de atrair o público feminino, o que geralmente não ocorre nos jogos eletrônicos com temáticas mais ligadas ao universo masculino, como os esportes e lutas. Esses jogos geram o pagamento de licenças e até mesmo a contratação de gravações de músicas exclusivas para jogos eletrônicos.

Em relação à distribuição da música, já há diversos artistas que têm disponibilizado seus trabalhos gratuitamente na rede mundial de computadores. Esse é um fenômeno que indica que, em certa medida, está sendo parcialmente flexibilizada a resistência da classe artística (ao menos em parte) à circulação de fonogramas, mesmo que não haja necessidade de pagamento por parte do público.

Paralelamente, dados divulgados recentemente ${ }^{20}$ mostram que o volume de músicas adquiridas em formato MP3 já ultrapassou o volume de CDs vendidos e ainda permanece crescendo. Ainda que haja a coexistência com formatos anteriores, esse parece ser um caminho

19 Alguns artistas chegaram a retirar suas músicas do serviço de streaming Spotify alegando a baixa qualidade do som, mas principalmente alegando que os valores repassados a título de pagamento pelos direitos autorais eram muito baixos, afora o fato de que essas plataformas desestimulam ainda mais a venda de discos. Nesse sentido, vide: <http://www.techtudo.com.br/listas/noticia/2015/07/tres-artistas-que-tiraram-suas-musicas-dospotify-e-o-caso-tidal.html>. Acesso em: 02 nov. 2015.

20 Ver o Relatório IFPI Digital Music Report 2014. Disponível em:<http://www.ifpi.org/downloads/Digital-Music-Report-2014.pdf >. Acesso em: 27 out. 2014. 
sem volta, uma vez que os aparelhos eletrônicos portáteis, principalmente os telefones celulares, já incorporaram a tecnologia MP3.

Diante dos problemas acima expostos, é cada vez mais comum que os grandes conglomerados da indústria fonográfica pleiteiem que os Estados façam alterações legislativas com vistas a proteger sua hegemonia. Contudo, há necessidade de ponderar os valores em jogo, sob pena de cerceamento da livre iniciativa, limitação dos direitos culturais ou mesmo do direito de propriedade.

Sabe-se que o direito costuma responder preteritamente aos ditames da realidade social, de modo que as alterações na legislação geralmente buscam regular uma situação que já está posta. Com relação às inovações tecnológicas da indústria fonográfica não está sendo diferente. Assim, podemos observar alguns movimentos no mercado fonográfico com interesse para o Direito: o movimento de fusão entre gravadoras, o lobby legislativo, por meio do qual se requer a intervenção indireta do Estado no domínio econômico sempre no sentido de ter seus interesses privados protegidos, e o papel do Escritório Central de Arrecadação e Distribuição ECAD.

No campo das fusões e aquisições, em meados dos anos 2000, a União Europeia teve posições contraditórias sobre a fusão entre as gravadoras Sony e BMG. A operação societária havia sido inicialmente aprovada pela Comissão Europeia ${ }^{21}$ em 2004, mas após a intervenção de uma associação de gravadoras independentes, o órgão reconsiderou seu posicionamento e anulou a decisão anterior no ano de 2006.

Posteriormente, a União Europeia determinou o reexame do caso pela Comissão Europeia. Assim, no ano de 2007, finalmente foi aprovada a operação societária, tendo como fundamentação da decisão, entre outros pontos, o fato de que não foram encontradas evidências de que a operação entre a Sony e a BMG poderia prejudicar as gravadoras independentes ou causar uma elevação nos preços para acesso do público à música ${ }^{22}$.

Outro movimento por parte das gravadoras e das empresas de tecnologia no sentido de se adequarem à nova realidade relacionada à circulação de música na internet tem sido a aquisição de plataformas digitais de música. Da perspectiva do consumidor/fruidor de música,

${ }^{21}$ A Comissão Europeia é o órgão executivo da União Europeia com competência para zelar pelo cumprimento da legislação nos Estados-Membros em decisões colegiadas. Ver mais em: <http://europa.eu/about-eu/institutions-bodies/european-commission/index_pt.htm\#goto_6>. Acesso em: 08 ago. 2015.

${ }^{22}$ Para mais informações sobre o processo em questão, vide caso COMP/M.3333 SONY/BMG. Disponível em: <http://ec.europa.eu/competition/mergers/cases/decisions/m3333_20071003_590_en.pdf>. Acesso em: 27 out. 2014. 
já era fato que as grandes gravadoras eram praticamente um oligopólio, sendo este caracterizado, entre outros fatores, pela presença de um pequeno número de empresas atuantes nesse mercado, embora isso não seja necessariamente um ato ilícito (DEL MASSO, 2007).

Destarte, é importante que os órgãos regulatórios permaneçam atentos a tais operações para que não venha a ocorrer uma excessiva concentração das majors nesse mercado relevante, notadamente nas empresas com potencial de crescimento na área de música, evitando que venham a causar retrocesso no processo de facilitação do acesso à música, seja por meio de canais pagos ou gratuitos.

O ECAD, nos termos da Lei n. ${ }^{\circ}$ 9.610/1998, tem natureza de associação privada, sem fins lucrativos, tendo como objetivo unificar a arrecadação e distribuição dos direitos autorais de execução pública musical. Contudo, quando se pensa na competência dada pela lei ao ECAD, surge para esta entidade o desafio de atuar na execução de música na internet, para que seja assegurado aos artistas o recebimento de seus direitos autorais.

Diante desse desafio imposto à entidade arrecadadora com a disseminação da música em meios eletrônicos, José Carlos Costa Netto (2015) faz três importantes questionamentos: (i) em que consistiria a modalidade de utilização de obras musicais e fonogramas que legitimam o ECAD a controlar, arrecadar e distribuir os direitos autorais, de natureza patrimonial, resultantes, no regular exercício de seu "mandato legal" para esse efeito; (ii) se essa modalidade de uso de obras musicais e fonogramas estaria sendo praticada na internet; e, uma vez configurada esta hipótese, (iii) em que condições se daria o exercício das atividades do ECAD e consequente licenciamento e cobrança, por este, do uso de obras musicais (e fonogramas).

Em relação ao primeiro questionamento, acerca da modalidade que legitimaria o ECAD a cobrar pela execução das músicas na internet e distribuir seus direitos, Netto (2015, p. 52) baseia-se na Lei n. ${ }^{\circ}$ 9.610/1998 para responder que a associação poderá desempenhar seu papel sempre que haja

[...] venda, locação ou qualquer outra forma de transferência ou posse dos bens intelectuais disponibilizados ao público (art. $5^{\circ}$, IV, da Lei n. 9.610/98); e que a oferta de obras ou produções distribuídas permita ao usuário realizar: (i) a "seleção da obra ou produção"; para percebê-la: (ii) "em um tempo ou lugar previamente determinados por quem formula a demanda"; e (iii) "nos casos em que o acesso às obras ou produções se faça por qualquer sistema que importe em pagamento pelo usuário" (art. 29, VII, da Lei n. 9.610/98).

A nosso ver, tais hipóteses abrangem tanto os downloads pagos, quanto os serviços pagos de streaming de música, e ainda uma quarta situação que é a exibição de propaganda nas 
plataformas gratuitas, como o Youtube, portanto tais modalidades de execução justificam e, mais que isso, exigem a ação do ECAD.

Quanto ao segundo e ao terceiro questionamentos, se as modalidades de uso de obras musicais e fonogramas estariam sendo praticadas na internet (download e streaming), é evidente que sim. Nesse sentido, mais uma vez Netto (2015, p. 58) aponta que cabe ao ECAD desempenhar seu papel para a proteção dos direitos autorais. Além disso, deverá o responsável pelo site

[...] obter autorização: (a) do ECAD, para a transmissão, disponibilização ou comunicação do conjunto de obras e fonogramas "colocados ao alcance do público" pelo site na internet; e (b) dos respectivos titulares em relação a cada obra/fonograma efetivamente selecionada pelo usuário/consumidor para sua audição (streaming) ou para armazenamento ou reprodução em seu computador pessoal (download), uma vez que este ato configure uma nova modalidade de utilização de obra ou fonograma musical, o que demandará, conforme previsão legal, autorização específica.

Dessa forma, vê-se que, mesmo com as inovações tecnológicas que tanto facilitaram o acesso do público à música, não há de se falar em perda dos direitos morais (também chamados de extrapatrimoniais, vide PAESANI, 2014, p. 46) e patrimoniais dos autores, o que se coaduna perfeitamente com os princípios da Ordem Econômica vigentes no ordenamento pátrio, sobretudo a valorização do trabalho humano, a existência digna, a justiça social e a propriedade privada. Dito de outra forma, não é porque a introdução de novas tecnologias facilita o acesso à música, que tais tecnologias autorizam a sua circulação gratuita, ao arrepio dos direitos autorais, pois o direito de autor permanece intocado no ordenamento jurídico, à vista do disposto no art. 5. $^{\circ}$, inciso XXVII, da Constituição Federal.

Por outro lado, se o próprio artista toma a iniciativa de disponibilizar seu trabalho via internet, de forma não onerosa, como meio de alcançar um número cada vez maior de pessoas, não há violação de direitos decorrente dessa divulgação que tem caráter de mera liberalidade sponte propria.

\section{CONCLUSÃO}

Há um esforço sendo feito no Brasil, nos últimos anos, para a delimitação do que seja a economia criativa, e ainda para a geração de dados estatísticos que sejam úteis para o planejamento das políticas públicas culturais, o que, no Brasil, ainda é incipiente. 
A lógica de produção e consumo de música está em plena transição no mundo: se antes essa relação era uma relação de compra e venda, sacramentada com a aquisição de um objeto físico, hoje a internet tem feito com que essa relação seja cada vez mais baseada na troca ou no compartilhamento. Esse cenário contraria os interesses já estabelecidos de empresas do setor musical, e por outro lado abre espaço para novos atores e novos modelos de produção e divulgação da música, criando novos desafios jurídicos.

\section{REFERÊNCIAS}

ADORNO, Theodor W.; HORKHEIMER, Max. Dialética do esclarecimento: fragmentos filosóficos. Rio de Janeiro: J. Zahar, 1985.

ANVERRE, Ari et al. Industrias culturales: el futuro de la cultura em juego. México: Fondo de Cultura Economica, Unesco, 1982.

BAGNOLI, Vicente. Direito econômico. São Paulo: Atlas, 2005. (Série Leituras Jurídicas, Volume 29).

BESSA, Virgínia de Almeida. Um bocadinho de cada coisa: trajetória e obra de Pixinguinha - História e Música Popular no Brasil nos anos 20 e 30. Dissertação (Mestrado em História) Faculdade de Filosofia, Letras e Ciências Humanas, Universidade de São Paulo, São Paulo, 2005 .

BRASIL. Constituição Federal da República Federativa do Brasil de 1988. Diário Oficial da União, Assembleia Nacional Constituinte, Brasília, DF, 05 out. 1988. Disponível em: <http://www.planalto.gov.br/ccivil_03/Constituicao/Constituicao.htm>. Acesso em: 07 nov. 2015.

Superior Tribunal de Justiça. Habeas Corpus n. ${ }^{\circ}$ 150.901 - MG (2009/0203910-2), Brasília, DF, 27 fev. 2011. Disponível em:

https://ww2.stj.jus.br/processo/revista/documento/mediado/?componente=ITA\&sequencial=1 258389\&num_registro=201301347300\&data=20130913\&formato=PDF. Acesso em 29 jan. 2016.

Superior Tribunal de Justiça. Agravo Regimental no Recurso Especial n. ${ }^{\circ}$ 1.356.243

- MS (AGRESP 2012/0252040-3), Brasília, DF, 12 mar. 2013. Disponível em: https://ww2.stj.jus.br/processo/revista/documento/mediado/?componente=ITA\&sequencial=1 $216368 \&$ num_registro $=201202520403 \&$ data $=20130318 \&$ formato=PDF. Acesso em 29 jan. 2016.

. Superior Tribunal de Justiça. Agravo Regimental no Recurso Especial n. ${ }^{0}$ 1.380.149 - RS (AGRESP 2013/0134730-0), Brasília, DF, 27 ago. 2013. Disponível em: https://ww2.stj.jus.br/processo/revista/documento/mediado/?componente=ITA\&sequencial=1 $258389 \&$ num_registro $=201301347300 \&$ data $=20130913 \&$ formato=PDF. Acesso em 29 jan. 2016.

COMMISSION OF THE EUROPEAN COMMUNITIES. Commission Decision of 03/X/2007 declaring a concentration to be compatible with the common Market and the EEA 
Agreement (Case No COMP/M.3333 n. Sony/ BMG). Disponível em: <http://ec.europa.eu/competition/mergers/cases/ decisions/m3333_20071003_590_en.pdf>. Acesso em: 27 out. 2014.

Mergers: Commission clears Universal's acquisition of EMI's recorded music business, subject to conditions. Disponível em: <http://europa.eu/rapid/press-release_IP-12999_en.htm>. Acesso em: 26 out. 2014.

COSTA NETTO, José Carlos. Estudos e pareceres de direito autoral. Rio de Janeiro: Forense, 2015.

DEL MASSO, Fabiano. Direito econômico: os limites jurídicos do imperialismo frente aos limites econômicos da soberania. Rio de Janeiro: Elsevier, 2007.

FEDERAÇÃO INTERNACIONAL DA INDÚSTRIA FONOGRÁFICA (IFPI). IFPI Digital Music Report 2014: lighting up new markets. Disponível em: <http://www.ifpi.org/downloads/Digital-Music-Report-2014.pdf>. Acesso em: 27 out. 2014.

IFPI Digital Music Report 2015: Chartin the path to sustainable growth. Disponível em: <http://www.abpd.hospedagemdesites.ws/wp-content/uploads/2015/01/Digital-MusicReport-2015.pdf >. Acesso em: 07 nov. 2015.

FUNDAÇÃO GETÚLIO VARGAS. Relatório com os dados da pesquisa Índice de Percepção do Cumprimento da Lei (IPCLBrasil) referente ao $4^{\circ}$ trimestre de 2013 e $1^{\circ}$ trimestre de 2014. São Paulo, jul. 2014. Disponível em: <http://bibliotecadigital.fgv.br/dspace/handle/10438/11861>. Acesso em: 07 nov. 2015.

HERSCHMANN, Micael. Indústria da música em transição. São Paulo: Estação das Letras e Cores, 2010.

INSTITUTO DE PESQUISA ECONÔMICA APLICADA (IPEA). Texto para discussão: panorama da economia criativa no Brasil. Brasília: Rio de Janeiro: IPEA, 2013. Disponível em: 〈http://repositorio.ipea.gov.br/bitstream/11058/2026/1/TD_1880.pdf〉. Acesso em: 07 nov. 2015.

ISAACSON, Walter. Steve Jobs: a biografia. Trad. Berilo Vargas, Denise Bottman e Pedro Maia Soares. São Paulo: Companhia das Letras, 2011.

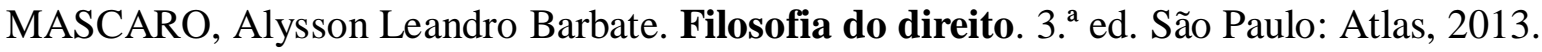

MOREL, Leonardo. Música e tecnologia: um novo tempo, apesar dos perigos. Rio de Janeiro: Beco do Azougue, 2010.

PAESANI. Liliana Minardi. Direito e internet: liberdade de informação, privacidade e responsabilidade civil. 7. ed. São Paulo: Atlas, 2014.

POLANYI, Karl. A grande transformação: as origens da nossa época. Trad. de Fanny Wrobel. 2. ed. Rio de Janeiro: Campus, 2011.

TINHORÃO, José Ramos. História social da música popular brasileira. São Paulo: Ed. 34, 2010. 
TOLILA, Paul. Cultura e economia: problemas, hipóteses, pistas. Trad. Celso M. Paciornik. São Paulo: Iluminuras/Itaú Cultural, 2007.

UNITED NATIONS EDUCATIONAL, SCIENTIFIC AND CULTURAL ORGANIZATION (UNESCO). CREATIVE Economy report 2013 special edition: widening local development pathways. New York; Paris: UNESCO, 2013. Disponível em:

<http://www.unesco.org/culture/pdf/creative-economy-report-2013.pdf>. Acesso em: 07 nov. 2015. 